\title{
Power Quality Enhancement in Residential Smart Grids through Power Factor Correction Stages
}

\author{
Víctor M. López-Martín, Francisco J. Azcondo, Senior Member, IEEE, and Alberto Pigazo, Senior Member, \\ IEEE
}

\begin{abstract}
The proliferation of non-linear loads and the increasing penetration of Distributed Energy Resources (DER) in Medium-Voltage (MV) and Low-Voltage (LV) distribution grids, make it more difficult to maintain the power quality levels in residential electrical grids, especially in the case of weak grids. Most household appliances contain a conventional Power Factor Corrector (PFC) rectifier, which maximizes the load Power Factor (PF) but does not contribute to the regulation of the voltage Total Harmonic Distortion $\left(T H D_{V}\right)$ in residential electrical grids. This manuscript proposes a modification for PFC controllers by adapting the operation mode depending on the measured $T H D_{V}$. As a result, the PFCs operate either in a low current Total Harmonic Distortion $\left(T H D_{I}\right)$ mode or in the conventional resistor emulator mode and contribute to the regulation of the $T H D_{V}$ and the $P F$ at the distribution feeders. To prove the concept, the modification is applied to a current sensorless Non-Linear Controller (NLC) applied to a single-phase Boost rectifier. Experimental results show its performance in a PFC front-end stage operating in Continuous Conduction Mode (CCM) connected to the grid with different $T H D_{V}$.
\end{abstract}

Index Terms-Harmonic distortion, Non-linear carrier control, Power factor correction.

\section{INTRODUCTION}

$\mathbf{H}$ ARMONIC limits in AC electrical grids are established by international standards and grid codes in order to ensure an efficient and proper operation of the subsystems and equipment connected to the grid, i.e. generators, loads and storage systems. The IEEE 519-2014 recommended practice and requirements for harmonic control in electric power systems [1] defines the limits on specific harmonics as well as on the current Total Harmonic Distortion $\left(T H D_{I}\right)$ and the current Total Demand Distortion $(T D D)$. Voltage and current harmonic distortion levels in electrical distribution systems are closely related, and the recommended $T H D_{V}$ limits in

Manuscript received August $2^{\text {nd }}, 2017$; revised October $3^{\text {rd }}, 2017$; accepted February $21^{\text {st }}, 2018$.

This work is funded by the Spanish Ministry of Science and Innovation through the project TEC2014-52316-R ECOTREND Estimation and Optimal Control for Energy Conversion with Digital Devices.

V. M. López-Martín is with the Power Electronics Area of IK4Ikerlan Technology Research Centre, Gipuzkoa, 20500 SPAIN e-mail: vmlopez@ikerlan.es.

F. J. Azcondo and A. Pigazo are with the University of Cantabria, Santander, 39005, SPAIN email: azcondof@unican.es; pigazoa@unican.es. distribution feeder tap points are likely exceeded if highly nonlinear loads are connected [2]. Exceeding voltage or current harmonic limits reduces the overall efficiency and might produce critical faults in weak or critical Electrical Power Systems (EPS). Among others, harmonic distortion causes heating of induction motors [3], accelerated aging of insulation [4] and harmonic resonances in capacitors for reactive power compensation [5]. Moreover, the harmonic distortion might affect the normal operation of medical equipment [6], [7] and distribution transformers in residential areas might suffer excessive loading, contributing to accelerate their aging [8].

The voltage harmonic distortion is mainly due to background harmonic sources, but residential loads contribute to increase the $T H D_{V}$, especially at $3^{r d}, 11^{\text {th }}$ and $13^{\text {th }}$ harmonics [9]. The effects of harmonics in residential areas are attenuated applying local or wide area mitigation approaches. Local ones are employed at the load or Distributed Energy Resource (DER) side, i.e. distributed generation and storage active front-ends, operated as adjustable harmonic impedances [10], [11] or including active power filter functionalities [12]. Wide area mitigation strategies are based on the coordination of local solutions, i.e. assigning compensation priorities to DERs [13]. The $T H D_{V}$ is improved by means of a droopbased approach [14], adjusting the equivalent DER admittance [15] or the deployment of distributed low-power low-voltage equipment for current harmonic filtering [16]. The integration of mitigation equipment at distribution feeder level, i.e. hybrid active power filters, also contributes to increasing the $P F$ and mitigating the effect of voltage disturbances on household appliances [17]-[19]. The compensation capability and availability using DERs is limited by their nominal rating, i.e. the LCL filter characteristics [20], and the operation mode, i.e. reactive power compensation [21], respectively. Dedicated local filtering solutions require the integration of additional equipment, increasing the overall cost, and involve a previous analysis of their impact on the grid [16], e.g. resonances in passive filters. Moreover, coordination of local solutions would require communications that increase the deployment complexity. In contrast, this manuscript proposes a local load side approach, with no extra hardware cost, achieved by extending the functionality of available PFCs.

PFC is widely employed in household appliances as an active front-end $\mathrm{AC} / \mathrm{DC}$ converter imposing unity power factor and supplying the load with the required constant DC 
voltage, while ensuring a high efficiency [22]. PFC stages have traditionally been utilized to improve the electrical power quality of EPS by emulating an input resistance for all system frequencies, so that in the case of a sinusoidal grid voltage the input current is sinusoidal with very high-frequency harmonic distortion, linked to the switching ripple. However, this resistor emulator behavior will result in line current harmonics in the case of harmonically distorted grid voltages, which would contribute to maintain $T H D_{V}$ levels at the Point of Common Coupling (PCC). A digitally controlled boost PFC with variable input impedance is proposed in [23]. The resistor emulator behavior is adjusted at different harmonic frequencies to contribute to the improvement of the grid stability.

Diverse works on PFC, impressing sinusoidal input currents $(\sin P F C$ ), have previously been published. In [24], [25], a sine wave generator is employed within the current loop to generate the appropriate reference current in single-phase systems. The sine wave generator can be replaced by a Phase-Locked Loop (PLL), as in [26], to generate the reference signal. Predictive controllers with a current sensor, showing immunity to input voltage distortion are utilized in [27]. These approaches are also employed in three-phase PFC in [28] and [29], respectively. The accurate synchronization of the modulation signals with the grid, the harmonics injected to compensate the distortion effect and the implementation of adaptive controllers to find the best response under distorted or non-distorted grid voltage motivate the utilization of digital controllers. The adoption of a sensorless solutions represents a step forward in terms of simplicity and reliability. As long as the resulting power factor is satisfactory, the elimination of the current sensor also eliminates the circuitry associated to the adoption of a reference for the current measurement, signal conditioning circuits and an analog-to-digital converter, in the case of a the controller implementation in a digital circuit. Since the current signal is not affected by the sensor size, the resulting controller covers a wider power rate. Several sensorless approaches have been presented recently. A voltage sensorless controller with adjustable power factor is proposed in [30] for a three-phase three-switch Vienna rectifier. A current sensorless technique with an artificial input voltage, stored in a Look-Up Table (LUT) to gain immunity under distorted input voltage, is presented in [31]. A more sophisticated technique, which precalculates the duty-cycle sequence, extending the load range of application with no input voltage or current acquisition, assuming that the reference is sinusoidal is presented in [32]. In [33], [34], a current sensorless technique is extended for multiphase current interleaved topologies. Since the actual current shape depends on the volt-seconds across the input inductor, the distortion of the $\mathrm{AC}$ input voltage produces input current distortion when the resistor emulator technique is used.

This paper proposes to improve the PF at the PCC by applying an adaptive PFC controller to the grid-connected $\mathrm{AC} / \mathrm{DC}$ converters of a residential grid, introducing the concept of Power Quality Enhancer (PQE) (Fig. 1). This PQE adapts the AC/DC converter current depending on the grid distortion. In this way, the PFC controller can operate in both resistor emulator and sinusoidal input current modes, allowing the $T H D_{V}$ minimization in residential electrical grids while maintaining maximum PF at the PCC. The proposed PQE PFC helps to reach advanced specifications required in residential smartgrids, such as peak load reduction [35] and energy management [36]. The paper is organized as follows. The main contributions are presented in Section II and III. Section II introduces the definitions of electrical power quantities and the effect of $T H D_{I}$ on the PF measured at the PCC and presents the PQE's operation principles. Details of the controller selected to develop the proof of concept [37] and the experimental results with the controller modified by the PQE are presented in Section III and IV respectively.

\section{Effect of the Proposed Controller on the Electrical PoWER Quality of RESIDENTIAL GRIDS}

The proposed PQE PFC consists of a conventional PFC stage with an enhanced digital controller, which adjusts the operation mode to maximize the $P F$ while contributing to reduce the $T H D_{V}$ at the PCC. The proposed controller modification is shown in Fig. 1, where the local $T H D_{V}$ measurement is employed to adjust the PFC operation mode. For analysis purposes, as depicted in Fig. 1, the Low-Voltage (LV) residential grid and household appliances are modeled through their Thévenin and Norton equivalents respectively. In [38], an individual residential house is modeled by its equivalent impedance and a current source, representing the linear and non-linear loads respectively. Considering that most of the Conventional Household Appliances (CHA) are connected to the grid through unidirectional AC/DC converters, the house impedance is approximated by a pure resistor, $R_{C H A}$, and a current source, corresponding to the sum of $N-1$ current harmonics $i_{C H A}^{\prime}$. Therefore, $i_{C H A}^{\prime}$ is given by (1), where $N$ represents the maximum harmonic order, $n$, of the CHA current:

$$
i_{C H A}^{\prime}(t)=\sum_{n \neq 1}^{N} i_{C H A, n}^{\prime}(t)
$$

Similarly, PQE PFC based household appliances are modeled through an equivalent resistor $R_{e q}$ and the harmonically distorted current $i_{P Q E}^{\prime}$,

$$
i_{P Q E}^{\prime}(t)=-k \frac{v_{P C C}(t)-v_{P C C, 1}(t)}{R_{e q}}=-k \frac{\sum_{n \neq 1}^{M} v_{n}(t)}{R_{e q}}=-k \frac{v_{P C C, H}(t)}{R_{e q}},
$$

calculated with the difference between the PCC voltage $\left(v_{P C C}\right)$ and its fundamental frequency component $\left(v_{P C C, 1}\right)$, with $M$ representing the maximum harmonic order of $v_{P C C}$. The factor $k$ is selected depending on the PCC THD $D_{V}$. By applying $k=0$, the PQE PFC behaves as a resistor emulator and with $k=1$, a sinusoidal input current is achieved. Moreover, it must be considered that, behaving as a front-end converter and assuming a resistive load $\left(R_{D C}\right)$ fed by the stationary voltage $\left(V_{D C}\right)$ imposed by the PQE PFC outer voltage controller (Fig. 1), the input power of the PQE PFC $\left(P_{P Q E}^{i n}\right)$ is imposed by the PFC output power, with no dependence on the operation mode selected through $k$. The 


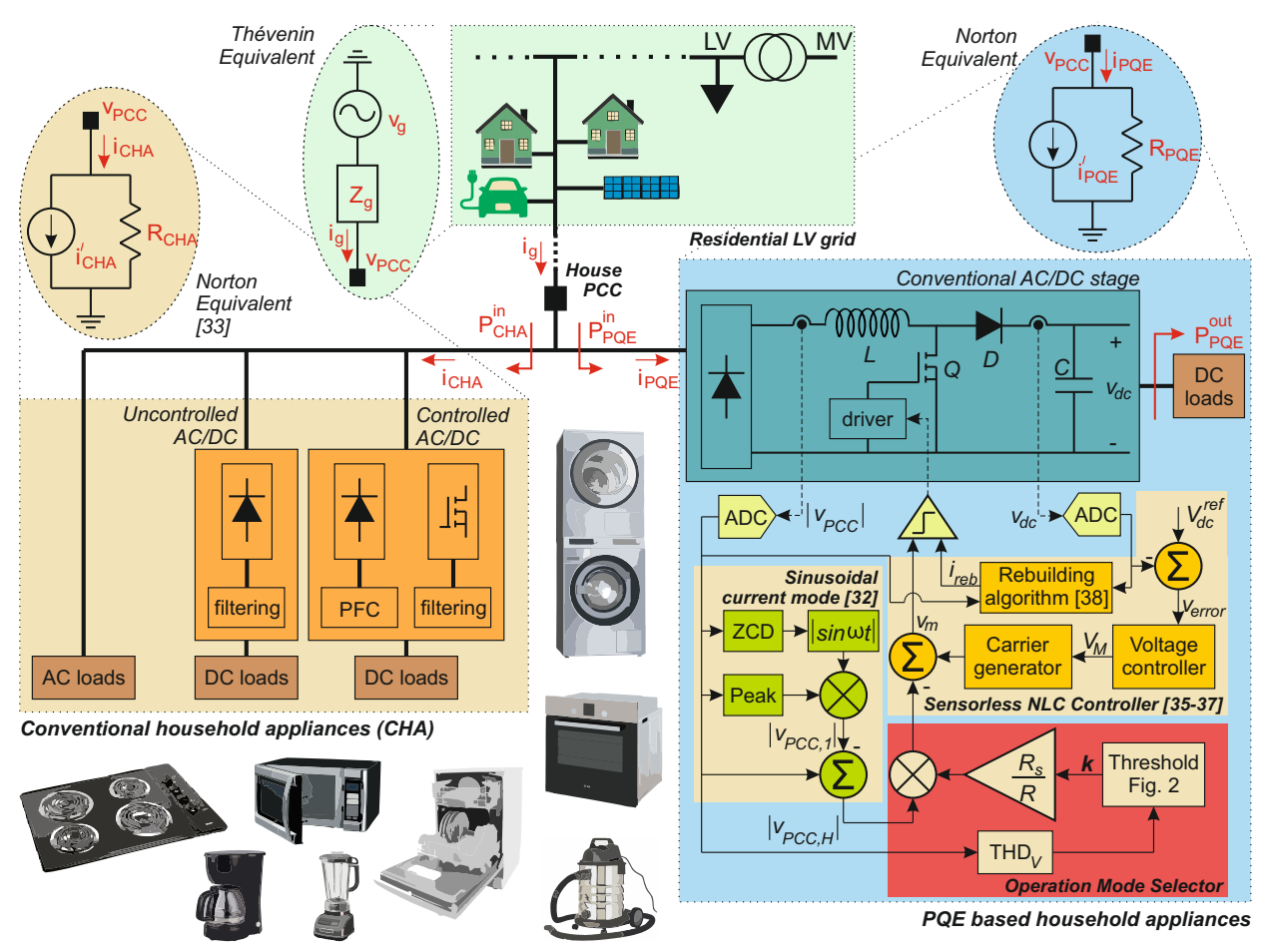

Fig. 1. Residential LV grid with household appliances feed through conventional AC/DC stages (without the proposed operation mode selector) and the proposed PQE controller.

LV electrical grid, from the point of view of the household appliances, is modeled through the impedance $Z_{g}$ and $v_{g}$ :

$$
v_{g}(t)=v_{g, 1}(t)+\sum_{n \neq 1}^{L} v_{g, n}(t),
$$

where $v_{g, 1}$ is the fundamental component of the grid voltage $\left(v_{g}\right), v_{g, n}$ its $n^{t h}$ harmonic component, and $L$ the maximum harmonic order of $v_{g}$, with $L \leq M<N$.

Assuming the approach in IEEE Std. 1459 [39], where the electrical power quantities under sinusoidal, non-sinusoidal, balanced and unbalanced conditions are defined, the instantaneous input power of the PQE PFC in Fig. 1 is written as

$$
p_{P Q E}^{i n}(t)=v_{P C C}(t) i_{P Q E}(t)=v_{P C C}(t)\left(\frac{v_{P C C}(t)}{R_{e q}}+i_{P Q E}^{\prime}(t)\right)
$$

Averaging $p_{P Q E}^{i n}$ over a grid period $T$ results in the active power of the PQE PFC $\left(P_{P Q E}^{i n}\right)$ :

$$
P_{P Q E}^{i n}(t)=\frac{1}{T} \int_{t-T}^{t} p_{P Q E}^{i n}(\tau) d \tau=\frac{V_{P C C, 1}^{2}}{R_{e q}}+\frac{(1-k)}{R_{e q}} \sum_{n \neq 1}^{M} V_{P C C, n}^{2}=\frac{P_{P Q E}^{o u t}(t)}{\eta}
$$

where it has been assumed that the PCC voltage and $R_{e q}$ change slowly enough, $\eta$ is the PQE PFC efficiency and $P_{P Q E}^{\text {out }}$ its output power, which, being employed as a front-end converter, means $P_{P Q E}^{\text {out }}=\frac{V_{D C}^{2}}{R_{D C}}$ (Fig. 1). Hence, the equivalent resistance of the PQE PFC is

$$
R_{e q}=\frac{\eta / 100}{P_{P Q E}^{o u t}} V_{P C C, 1}^{2}\left(1+(1-k) T H D_{V}^{2}\right)
$$

which, having $P_{P Q E}^{o u t}$ imposed by the PFC outer voltage control loop, depends on the PCC voltage and the selected operation mode $(k)$. As a consequence, in the resistive emulator mode $(k=0) R_{e q}$ increases with the $T H D_{V}$. For simplicity's sake, it will be assumed that $\eta=100 \%$ in the subsequent analysis.

\section{A. PF at the PCC with the PQE PFC controller in both operation modes}

As will be proved in this subsection, the PF at the PCC can be improved by the PQE PFC in household appliances. The $\mathrm{PF}$ is evaluated through the definition in IEEE Std. 1459 [39] and both operation modes $(k=1$ and $k=0)$ are considered. From Fig. 1:

$$
\begin{array}{r}
P F=\frac{P_{P Q E}^{i n}+P_{C H A}^{i n}}{V_{P C C} I_{g}}=\frac{P_{P Q E}^{\text {out }}+\frac{V_{P C C, 1}^{2}\left(1+T H D_{V}^{2}\right)}{R_{C H A}}+P_{\text {harm }}}{\sqrt{V_{P C C, 1}^{2}\left(1+T H D_{V}^{2}\right)} \sqrt{I_{g}^{2}}} \\
\text { and } P_{\text {harm }}=\sum_{n \neq 1}^{M} V_{P C C, n} I_{C H A, n}^{\prime} \cos \theta_{n},
\end{array}
$$

where $P_{C H A}^{i n}$ is the active power due to the CHA and the term $P_{\text {harm }}$ corresponds to the active power transferred by the harmonic current components due to the conventional load nonlinearities and the harmonic distortion of the PCC voltage.

The overall household appliance current $\left(i_{g}\right)$ can be obtained from Kirchhoff's Current Law (KCL) at the PCC:

$$
\begin{aligned}
i_{g}(t) & =i_{P Q E}(t)+i_{C H A}(t) \\
& =i_{P Q E}^{\prime}(t)+i_{C H A}^{\prime}(t)+\frac{R_{e q}+R_{C H A}}{R_{e q} R_{C H A}} v_{P C C}(t)
\end{aligned}
$$


and, then, the squared rms value of the overall household appliance current is evaluated using (10):

$$
\begin{aligned}
I_{g}^{2} & =\frac{1}{T} \int_{t-T}^{t} i_{g}^{2}(\tau) d \tau=\frac{\left(1+(1-k)^{2} T H D_{V}^{2}\right)\left(P_{P Q E}^{\text {out }}\right)^{2}}{V_{P C C, 1}^{2}\left(1+(1-k) T H D_{V}^{2}\right)^{2}} \\
& +\frac{2 P_{P Q E}^{\text {out }}(1-k) P_{\text {harm }}}{V_{P C C, 1}^{2}\left(1+(1-k) T H D_{V}^{2}\right)}+\frac{2 P_{P Q E}^{\text {out }}}{R_{C H A}} \\
& +\frac{V_{P C C, 1}^{2}}{R_{C H A}^{2}} T H D_{I_{C H A}^{\prime}}^{2}+\frac{2 P_{\text {harm }}}{R_{C H A}}+\left(1+T H D_{V}^{2}\right) \frac{V_{P C C, 1}^{2}}{R_{C H A}^{2}}
\end{aligned}
$$

Substituting (10) into (7), the PF at the PCC is obtained:

$$
P F=\frac{P_{P Q E}^{\text {out }}+\frac{V_{P C C, 1}^{2}\left(1+T H D_{V}^{2}\right)}{R_{C H A}}+P_{\text {harm }}}{\sqrt{S_{0}^{2}+S_{k}^{2}}},
$$

where $S_{0}^{2}$ and $S_{k}^{2}$ are given in (12) and (13) respectively:

$$
\begin{aligned}
& S_{0}^{2}=\frac{2 V_{P C C, 1}^{2}\left(1+T H D_{V}^{2}\right)}{R_{C H A}}\left(P_{P Q E}^{\text {out }}+P_{\text {harm }}+\frac{V_{P C C, 1}^{2}}{2 R_{C H A}}\left(1+T H D_{V}^{2}+T H D_{I_{C H A}^{\prime}}^{2}\right)\right) \\
& S_{k}^{2}=\frac{1+T H D_{V}^{2}}{1+(1-k) T H D_{V}^{2}}\left(\frac{1+(1-k)^{2} T H D_{V}^{2}}{1+(1-k) T H D_{V}^{2}}\left(P_{P Q E}^{\text {out }}\right)^{2}+2(1-k) P_{P Q E}^{\text {out }} P_{\text {harm }}\right)
\end{aligned}
$$

Eq. (12) does not depend on $k$ while $S_{k}^{2}$ depends on the selected operation mode. Considering that $k \in[0,1]$ and $P_{\text {harm }}+P_{P Q E}^{\text {out }}>0$, the value of $k$ required to maximize the $\mathrm{PF}$ is obtained from (11) by minimizing the denominator, resulting in

$$
k=\frac{P_{\text {harm }}\left(1+T H D_{V}^{2}\right)}{\left(P_{\text {harm }}+P_{P Q E}^{\text {out }}\right) T H D_{V}^{2}}=\frac{1+\frac{1}{T H D_{V}^{2}}}{1+\frac{P_{P Q E}^{\text {out }}}{P_{\text {harm }}}} .
$$

Identification of the optimal continuous value of $k \in[0,1]$ requires $P_{\text {harm }}$ to be known. In the following analysis only $k=0$ or $k=1$ values are allowed. Then, depending on the selected operating mode for the PQE PFC, the overall PF becomes

$$
P F= \begin{cases}\frac{P_{P Q E}^{\text {out }}+\frac{V_{P C C, 1}^{2}\left(1+T H D_{V}^{2}\right)}{R_{C H A}}+P_{\text {harm }}}{\sqrt{S_{0}^{2}+\left(1+T H D_{V}^{2}\right)\left(P_{P Q E}^{\text {out }}\right)^{2}}}, & \begin{array}{l}
k=1 \\
\text { (sinusoidal) }
\end{array} \\
\frac{P_{P Q E}^{\text {out }}+\frac{V_{P C C, 1}^{2}\left(1+T H D_{V}^{2}\right)}{R_{C H A}}+P_{\text {harm }}}{\sqrt{S_{0}^{2}+\left(P_{P Q E}^{\text {out }}\right)^{2}+2 P_{P Q E}^{\text {out }} P_{\text {harm }}}}, & k=0 \\
\text { (resistive) }\end{cases}
$$

where $P_{P Q E}^{\text {out }}$ only depends on the DC load of the PQE PFC, being independent on the selected $k$. Under the same grid and load conditions, a change in $k$ results in a different $\mathrm{PF}$ at the PCC. The operation in a sinusoidal line current mode is the most beneficial if the following relationship is fulfilled

$$
\left(1+T H D_{V}^{2}\right)\left(P_{P Q E}^{\text {out }}\right)^{2}<\left(P_{P Q E}^{\text {out }}\right)^{2}+2 P_{P Q E}^{\text {out }} P_{\text {harm }}
$$

because this mode results in higher PF at the PCC than the resistive emulator mode. This condition can also be expressed as

$$
T H D_{V}<\sqrt{2} \sqrt{\frac{P_{h a r m}}{P_{P Q E}^{\text {out }}}}
$$

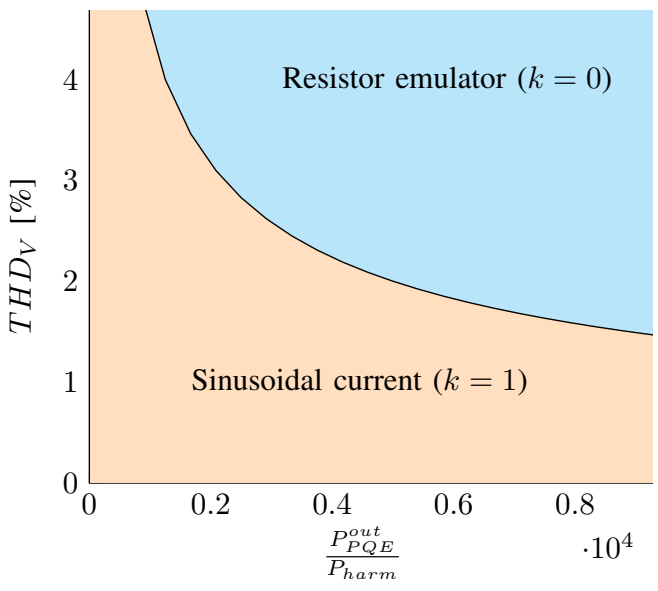

Fig. 2. Operation region of the PQE PFC resulting in a higher PF $\left(P_{\text {harm }}>0\right)$.

Therefore, the active power ratio $\frac{P_{P Q E}^{o u t}}{P_{\text {harm }}}$, which depends on the nonlinear household appliances, and the measured $T H D_{V}$ at the PCC are used to select the most appropriate $k$. It must be considered that in the case of $P_{\text {harm }} \leq 0$, (16) cannot be verified and the resistive emulator mode is the most beneficial. Condition (16) is depicted in Fig. 2, showing the operation mode that results in a better PF at the PCC depending on the $T H D_{V}$ and the $\frac{P_{P Q E}^{\text {out }}}{P_{\text {harm }}}$ ratio. By increasing the power processed through the proposed PQE PFCs, the overall PF will benefit from the resistor emulator mode $(k=0)$ or the sinusoidal current mode $(k=1)$ depending on the measured $T H D_{V}$ at the PCC. In the case of highly non-linear loads as CHA, the most beneficial operation mode in residential EPS (with relatively low $T H D_{V}$ ) is the sinusoidal current one $(k=1)$. If the power processed through the PQE PFCs is high enough, the resistor emulator mode $(k=0)$ would be the most beneficial one. As an illustrative example, given a certain $\frac{P_{P Q E}^{o u t}}{P_{h a r m}}$, for instance 5000 , the threshold value provided by eq. (17) is $2 \%$. Below this $T H D_{V}$ value, the PQE must operate in sinusoidal current mode to maximize the overall PF.

The overall system conditions allowing the operation in a sinusoidal line current mode are evaluated below. As has been established before, this operation mode requires

$$
P_{\text {harm }}=\sum_{n \neq 1} \frac{1}{2} \Re e\left\{\vec{v}_{p c c}(n \omega) \times \vec{i}_{C H A}^{*}(n \omega)\right\}>0,
$$

where $\vec{v}_{p c c}$ and $\vec{i}_{C H A}^{\prime}$ are the phasor representation of the PCC voltage and the harmonic current due to the conventional loads in Fig. 1. By applying the superposition principle, and replacing $Z_{g}$ in Fig. 1 by $R_{g}+j L_{g}$, the condition (18), in terms of IEEE Std. 1459 definitions and considering the PQE PFC operation mode through $k$, can be rewritten as

$$
P_{\text {harm }}=P_{A}(k)-P_{B}(k)>0 \rightarrow P_{A}(k)>P_{B}(k)
$$

where the term $P_{A}(k)$, given in (20), corresponds to the power term resulting from the interaction of conventional non-linear loads and the grid voltage harmonics while $P_{B}(k)$, the power term which is consequence of the voltage across the grid 


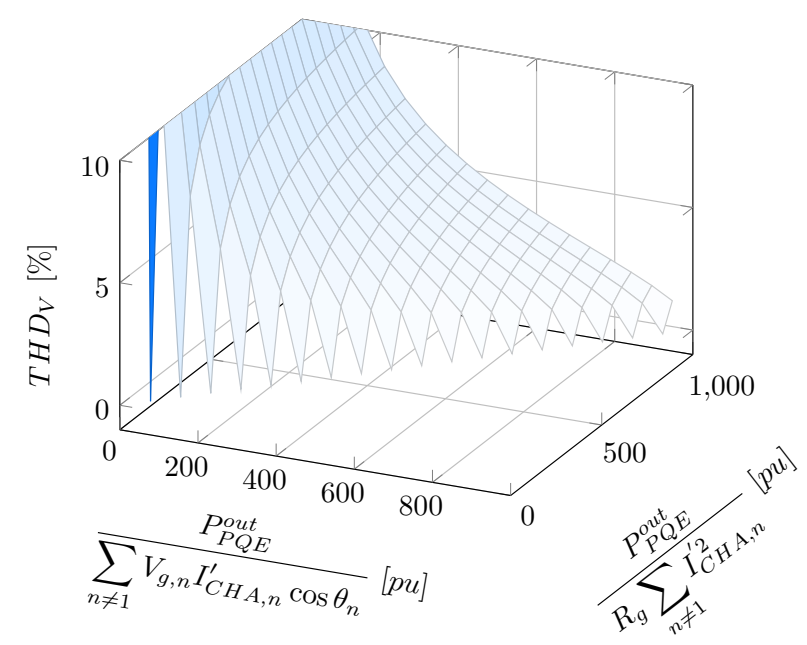

Fig. 3. Operation surface of the PQE PFC resulting in a higher PF $\left(R_{C H A} \approx R_{e q}, R_{g}<<R_{C H A}, L_{g}<<R_{g}\right)$.

impedances due to the harmonics caused by the non-linear loads, is directly computed by (21).

From (19), having a grid voltage harmonically distorted above a given rate, the PFC operation in sinusoidal input current mode improves the PF. Otherwise, the resistor emulator mode results in better PF. Under the assumption of $R_{C H A} \approx$ $R_{e q}, R_{g}<<R_{C H A}, L_{g}<<R_{g}$ and considering that $I_{C H A, n}^{\prime}$ decreases while increasing $n$, (19) can be approximated by

$$
\sum_{n \neq 1} V_{g, n} I_{C H A, n}^{\prime} \cos \theta_{n}>R_{g} \sum_{n \neq 1} I_{C H A, n}^{\prime 2}
$$

where the contribution of the grid voltage harmonics to the active power must be greater than the effect of the harmonic currents through the grid impedance.

By substituting (22) into (17), under the previous assumptions, the following relationship must be accomplished in order to improve the overall PF by operating in sinusoidal input current mode

$$
\begin{aligned}
T H D_{V} & <\sqrt{2} \sqrt{\frac{P_{\text {harm, grid }}}{P_{P Q E}^{\text {out }}}-\frac{P_{\text {harm }, R_{g}}}{P_{P Q E}^{\text {out }}}} \\
& \approx \sqrt{2} \sqrt{\frac{\sum_{n \neq 1} V_{g, n} I_{C H A, n}^{\prime} \cos \theta_{n}}{P_{P Q E}^{\text {out }}}-\frac{R_{g} \sum_{n \neq 1} I_{C H A, n}^{\prime 2}}{P_{P Q E}^{\text {out }}}}
\end{aligned}
$$

Condition (23) is depicted in Fig. 3. The sinusoidal input current mode leads to a higher PF between the depicted surface and the $T H D_{V}=0 \%$ plane, i.e. underneath the surface.

\section{B. PQE PFC concept simulations}

The PQE PFC concept has been tested with simulations considering a typical feeder in a distribution grid. A scenario with 20 houses connected to the feeder, where the house and grid parameters have been obtained from [40]-[42], and CHA are a combination of Compact Fluorescent Lights (CFL) and Personal Computers (PC) adjusted to a nominal house power of $2.2 \mathrm{~kW}$ and a $230 \mathrm{~V} 50 \mathrm{~Hz}$ feeder voltage with harmonic distortion levels due to $5^{\text {th }}$ and $7^{\text {th }}$ harmonics, $L_{g}=0.08$ $m H, R_{g}=60 m \Omega$. The simulations are carried out changing the number of conventional non-linear loads and PFCs $\left(\frac{P_{P F C}^{i n}}{P_{P C C}}\right)$, while maintaining the overall active power at the PCC $\left(P_{P C C}\right)$, and measuring the overall $P F$ at the PCC according to the scheme depicted in Fig. 1. The simulations have been carried out in MatLab/Simulink and show the applicability of the PQE PFC concept in residential EPS.

Fig. 4 shows the PF at the PCC due to the PQE PFC. The $\mathrm{PQE}$ controller selects the most beneficial operation mode ( $k=1$ or $k=0$ ) following the approach in Section II.A. The alternative operation mode, discarded by the PQE, is also plotted for comparison purposes. As it is shown, the PCC PF increases by replacing conventional loads with PFCs but, at low grid $T H D_{V}$ (due to $v_{g}$ in Fig. 1), $k=1$ performs better than $k=0$ mode and the PQE controller assumes this operation mode to maximize the PF at the PCC. With $\mathrm{PQE}$ applying $k=1$, and $k=0$ discarded, the maximum difference between modes arises at pure sinusoidal grid voltage and $\frac{P_{P F C}^{i n}}{P_{P C C}}=50 \%$, where the PQE increases the $P F$ from 0.988 to 0.989 , meaning $120 \mathrm{VA}$. If all the power is processed through PQE PFCs and the grid $T H D_{V}$ reaches $8 \%$, then $k=0$ increases the $\mathrm{PF}$ with respect the $k=1$ case, from $P F=0.995$ up to virtually unity, reducing the reactive component by $4.17 \mathrm{kVA}$. The worst $P F$ corresponds to only CHA loads, with $P F=0.955$.

\section{ImPLEMENTATION OF THE PQE CONTROLLER}

According to the previous discussion, a sinusoidal line current contributes to increasing the efficiency and performance of the residential EPS within the conditions depicted in Fig. 2. The PQE can be included in any PFC controller. Without losing generality, this section describes the proposed singlephase sensorless controller for PFC achieving this behavior. The proposed approach extends the performance of the digital sensorless Non-Linear Controller (NLC) in PFC [37], [43][46] by including a new term, which depends on the measured voltage harmonic distortion and the DC load. This term achieves low $T H D_{I}$ current impression regardless of the line voltage distortion.

$$
\begin{aligned}
& P_{A}(k)=\sum_{n \neq 1} V_{g, n} I_{C H A, n}^{\prime} \frac{\left(R_{g} R_{e q}+(1-k) R_{g} R_{C H A}+R_{C H A} R_{e q}\right) \cos \theta_{n}+n \omega L_{g}\left(R_{e q}+(1-k) R_{C H A}\right) \sin \theta_{n}}{\left(R_{g} R_{e q}+(1-k) R_{g} R_{C H A}+R_{C H A} R_{e q}\right)^{2}+n^{2} \omega^{2} L_{g}^{2}\left(R_{e q}+(1-k) R_{C H A}\right)^{2}} \\
& P_{B}(k)=\sum_{n \neq 1} I_{C H A, n}^{\prime 2} \frac{R_{g}\left(R_{g} R_{e q}+(1-k) R_{g} R_{C H A}+R_{C H A} R_{e q}\right)+n^{2} \omega^{2} L_{g}^{2}\left(R_{e q}+(1-k) R_{C H A}\right)}{\left(R_{g} R_{e q}+(1-k) R_{g} R_{C H A}+R_{C H A} R_{e q}\right)^{2}+n^{2} \omega^{2} L_{g}^{2}\left(R_{e q}+(1-k) R_{C H A}\right)^{2}}
\end{aligned}
$$




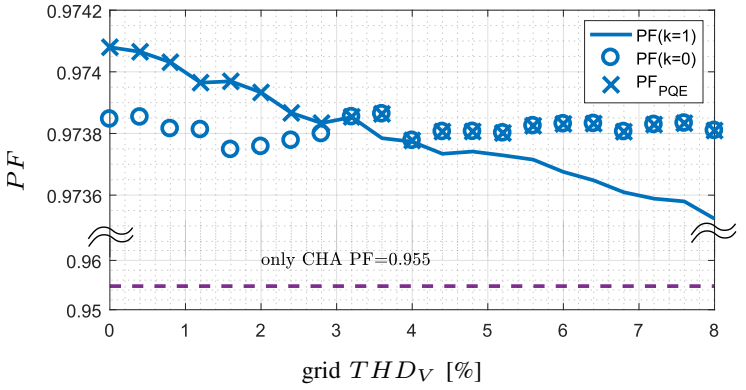

(a)

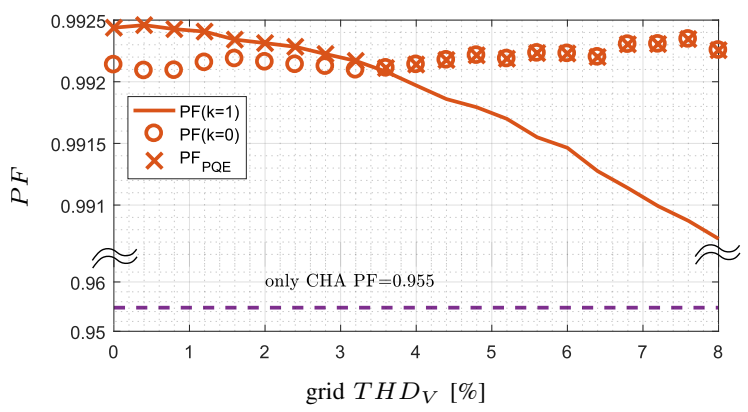

(b)

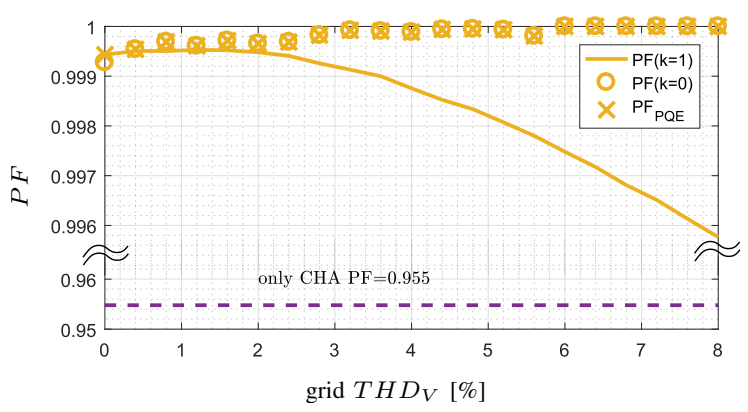

(c)

Fig. 4. $P F$ at the $P C C$ due to the $P Q E$ and the discarded operation modes. a) $\frac{P_{P F C}^{i n}}{P_{P C C}}=25 \%$ b) $\frac{P_{P F C}^{i n}}{P_{P C C}}=60 \%$ c) $\frac{P_{P F C}^{i n}}{P_{P C C}}=90 \%$.

The NLC has been selected to connect this proposal with recent research work [47]. It shows a better dynamic performance compared to the linear controllers based on current averaging, especially for high-frequency grids. The main drawback is its poor noise immunity, overcome with the sensorless approach. A typical bandwidth of the linear current control loop recommended for utility line frequencies $(50-60 \mathrm{~Hz})$ is units of $k \mathrm{~Hz}$, with switching frequencies close to $100 \mathrm{kHz}$. If the line frequency increases, the typical distortion around the line zero-crossing makes it impossible to fulfill the harmonic limits. This issue is addressed in detail in [48] and [49]. Nonlinear controllers solve this problem, achieving responses as fast as the switching cycle [50]. The NLC sensorless controller represents a solution suitable for universal voltage ( 85 to $250 V_{r m s}$ and grid frequencies up to $400 \mathrm{~Hz}$ ), being attractive to prove the contribution of this paper.

The NLC is defined for the Boost converter switching at constant frequency, $f_{s w}=1 / T_{s w}$, and with Pulse-Width

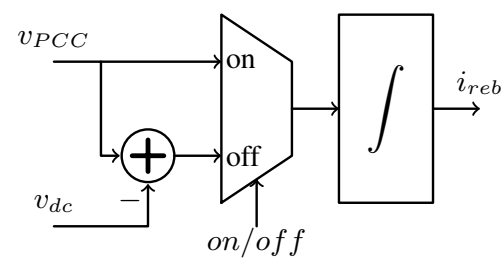

Fig. 5. Block diagram of the basic current rebuilding algorithm.

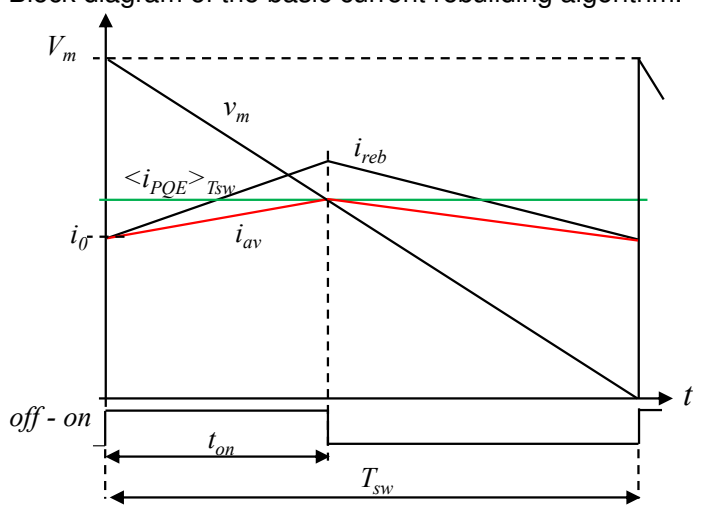

Fig. 6. Representation of the NLC variables.

Modulation (PWM). A variable $i_{a v}(t)$ is calculated during each switching period, $0 \leq t \leq T_{s w}$, from $i_{r e b}(t)$, which is the output of the current rebuilding algorithm [51] shown in Fig. 5 and $i_{0}$, which is the current at the beginning of the switching period. The carrier signal, $v_{m}$, and $i_{a v}$ are compared to set the duty cycle, $d$.

$$
i_{a v}(t)=\frac{i_{r e b}(t)+i_{0}}{2},
$$

It is assumed that $i_{a v}\left(d T_{s w}\right)$ represents the average current over the switching period when the estimation errors are properly compensated i.e.

$$
i_{a v}\left(d T_{s w}\right)=\left\langle i_{P Q E}\right\rangle_{T_{s w}}
$$

To derive the $\sin P F C$ NLC for the PQE PFC, $\left\langle i_{P Q E}\right\rangle_{T_{s w}}$ is firstly assumed sinusoidal, so that

$$
\left\langle i_{P Q E}\right\rangle_{T_{s w}}=\frac{P_{P Q E}^{i n}}{V_{P C C, 1}} \sqrt{2} \sin (\omega t)
$$

The controller with $k=0$ results in an input current $i_{P Q E}$, i.e. $\left\langle i_{P Q E}\right\rangle_{T_{s w}}$, proportional to $v_{P C C}$ using the NLC technique as shown in Fig. 6 and summarized with the expression

$$
\left\langle i_{P Q E}\right\rangle_{T_{s w}}=\frac{V_{D C}}{R_{e q}}(1-d),
$$

with the duty cycle $d=t_{o n} / T_{s w}$ and the carrier signal $v_{m}$, whose amplitude, $V_{m}$, is proportional to the input power, $P_{P Q E}^{i n}$, and also represents the inverse of the emulated resistance $R_{e q}$.

$$
v_{m}=V_{m}\left(1-\frac{t}{T_{s w}}\right), 0 \leq t \leq T_{s w}
$$

with 


$$
V_{m}=R_{s} \frac{V_{D C}}{R_{e q}}=R_{s} \frac{V_{D C}}{V_{P C C, 1}^{2}} P_{P Q E}^{i n},
$$

where $R_{s}$ is a fictitious sensing resistance, which gives consistency to the units of the variables in the rebuilding algorithm.

Considering a distorted AC line voltage at the PCC according to (3), (26) can be rewritten as a function of $v_{P C C, 1}$

$$
\left\langle i_{P Q E}\right\rangle_{T_{s w}}=\frac{v_{P C C, 1}}{R}=\frac{v_{P C C}-v_{P C C, H}}{R}
$$

where $R$ provides proportionality between the input current $i_{P Q E}$ and the fundamental component of the voltage $v_{1}$.

Assuming that the converter operates in the Continuous Conduction Mode (CCM), the ideal quasi-static conversion characteristic of the PWM-controlled Boost converter with duty cycle $d$ is given by

$$
v_{P C C}=V_{D C}(1-d)
$$

and introducing (31) into (30) results in

$$
\left\langle i_{P Q E}\right\rangle_{T_{s w}}=\frac{1-d}{R} V_{D C}-\frac{k}{R} v_{P C C, H}
$$

Around the AC line zero crossing, where the converter operates in the Discontinuous Conduction Mode (DCM), a little distortion in the input current occurs as is explained in detail in [34] for the traditional NLC controller, affecting this low $T H D_{I}$ controller in the same way. In CCM, the NLC control achieves power factor correction through a comparison of signals (Fig. 6) that finds an easy implementation in a digital circuit.

The output voltage is approximated in (31) and (32) by its DC value (small ripple approximation) at the specified reference level $V_{D C}=V_{D C}^{r e f}$. The first term in (32), $V_{D C}(1-d) / R$, is similar to the NLC control law shown in [34] or the Linear Peak Current-Mode (LPCM) control in [52]. The second term, $v_{P C C, H} / R$, corresponds to line harmonic voltage distortion and factor $k$ allows the $T H D_{V}$ to be considered. The duty cycle command is obtained by comparing the digitized signals $i_{a v}(t)$ and a leading-edge saw-tooth carrier signal $v_{m}(t)$, redefined as

$$
v_{m}(t)=V_{m}\left(1-\frac{t}{T_{s w}}\right)-k \frac{v_{P C C, H}}{R} R_{s}, \quad 0 \leq t \leq T_{s w}
$$

where $V_{m}=R_{s} V_{D C} / R$. For the current sensorless application, $R_{s}=1 \Omega$ is arbitrarily adopted, where the value $R$ changes with the load and is set by the outer voltage loop with $V_{m}$ [43]. The second term in (33), $k R_{s} v_{P C C, H} / R$, offsets the carrier signal in each switching period, meaning a lowfrequency harmonic content in the carrier signal. With the factor $k$ defined in the previous section, the operation mode of the PFC is selected. Fig. 7 shows the waveforms defined in (33) and the lowest harmonics over a half line cycle, for an input voltage with a $T H D_{V}=6 \%$ with harmonics $v_{P C C, 3}=0.05 \sqrt{2} \sin (3 \omega t), v_{P C C, 5}=0.03 \sqrt{2} \sin (5 \omega t+\pi)$ and $v_{P C C, 7}=0.01 \sqrt{2} \sin (7 \omega t)$. For clarification purposes, $T_{s w}$ has been depicted much longer than the actual implemented switching period.

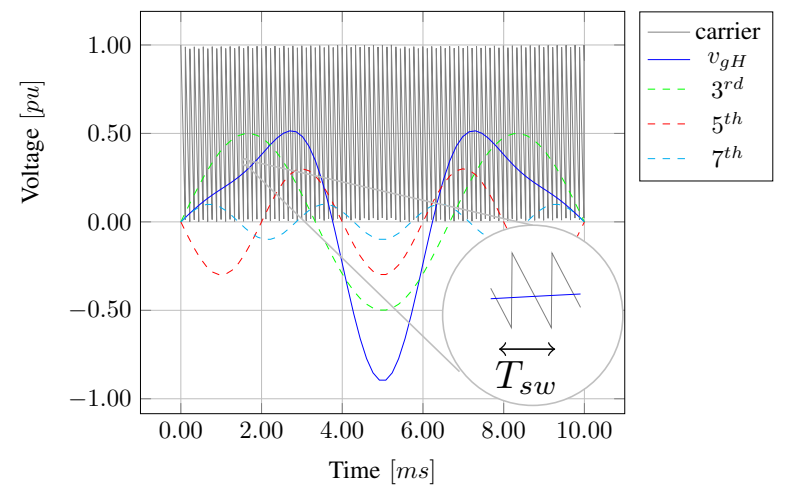

Fig. 7. Carrier and $v_{P C C, H}$ in an example of input voltage with $T H D_{V}=6 \%$.

In order to obtain the second term in (33), an Analog-toDigital Converter (ADC) digitizes the input voltage, $v_{P C C}$, and a sinusoidal pattern is synchronized with the utility line-toneutral voltage using a digital Zero-Crossing Detector (ZCD). An input voltage peak detector is used to approximate the value of $v_{P C C, 1}$ to $v_{P C C, 1} \approx V_{P C C, p e a k} \sin (\omega t)$. Different approaches, such as the zero-phase detector circuit in [53] or PLLs can be applied here, the last one being the preferred approach to achieve immunity to input voltage distortion [54], [55], as is included in certain PFC proposals [56], [57]. Hence, (30) is rewritten as

$$
\left\langle i_{P Q E}\right\rangle_{T_{s w}}=\frac{V_{P C C, p e a k}}{R} \sin (\omega t),
$$

where $\omega$ is evaluated on a period-to-period basis and, assuming slow harmonic variations, their effect on $\omega$ are negligible. Estimation errors occur due to the phase displacement of $\sin (\omega t)$ and the fundamental in $v_{P C C}$, which are caused by the relative phase and magnitude of the voltage harmonics in $v_{P C C}$. Replacing the ZCD by a PLL avoids such effects, however, it must be considered that the $T H D_{V}$ in residential feeders is usually in the range $(1 \%, 3 \%)$ [58], which limits the potential phase errors to less than a maximum 3.3 degrees. The effects of the voltage harmonic distortion on the estimation of $V_{P C C \text {,peak }}$ are mitigated by the outer voltage control loop of the PQE, which adjusts the amplitude of $i_{P Q E}$.

If $i_{P Q E}$, which is purely sinusoidal according to (30), is initially different to the one required by the load, then the outer voltage loop modifies $V_{m}$, and therefore $R$, to set the input current according to the required power.

A block diagram of the Boost rectifier with the low $T H D_{I}$ controller and its connection to the operation mode selector is shown in Fig. 1. The proposed circuit obtains a signal that represents the input voltage distortion with $\left|v_{P C C, H}\right| \approx$ $\left|v_{P C C}\right|-v_{P C C, p e a k}|\sin (\omega t)|$.

The calculation of the voltage distortion can be improved using a specific algorithm implemented in a digital device, i.e. a microcontroller or an Field Programmable Gate Array (FPGA), the Fast Fourier Transforms (FFT) is a good choice to obtain the harmonic content of a variable, with dedicated blocks to compute this, like in [59], [60], but this requires 


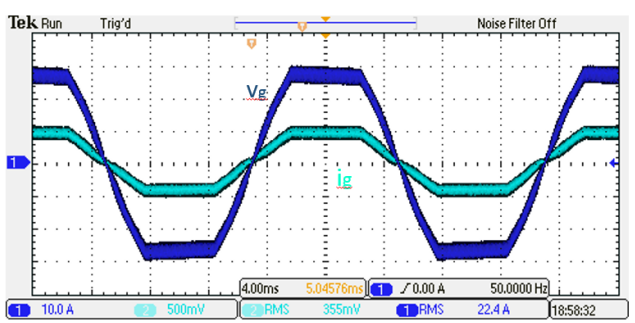

(a)

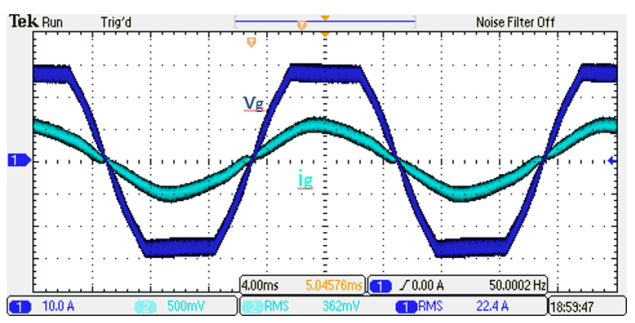

(b)

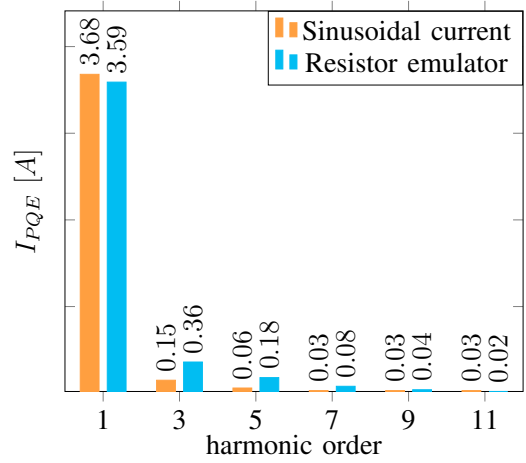

(c)

Fig. 8. Experimental results of PQE PFC at $50 \mathrm{~Hz}$. Voltage and current waveforms in a) resistor emulator mode $(k=0)$, b) sinusoidal current mode $(k=1)$ and c) measured spectra in both operation modes.

lots of resources. On the other hand, the outer loop makes an accurate calculation of the distortion term unnecessary and the value of each harmonic voltage is not needed, so the total harmonic voltage $v_{P C C, H}$ is computed, with the outer voltage loop setting the value of $V_{m}$. In steady-state, $R$ automatically defines the amplitude $\left\langle i_{P Q E}>_{T_{s w}}\right.$ [46].

Note that with the PQE controller, the load viewed by the grid, $R_{e q}$, is now a function of the input voltage phase. In steady state, and for a defined input power $P_{P Q E}^{i n}$, the input current in (26), and (34) yields an expression for $R$

$$
R=\frac{V_{P C C, p e a k} V_{P C C, 1}}{P_{P Q E}^{i n} \sqrt{2}}
$$

From (35), it is possible to obtain the expression for the equivalent resistance $R_{e q}$

$$
R_{e q}=R \frac{v_{P C C, 1}}{v_{P C C}}
$$

\section{EXPERIMENTAL RESULTS}

With the addition of the proposed modification to the NLC controller, the parameter $k$ selects the preferred behavior

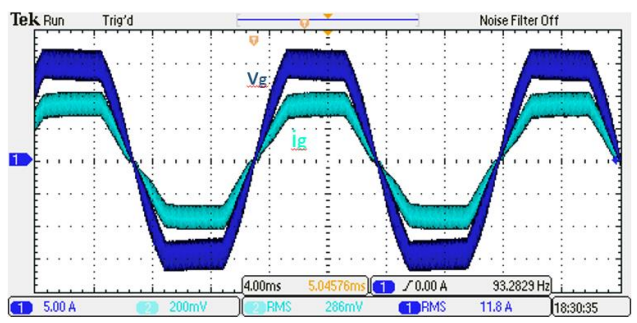

(a)

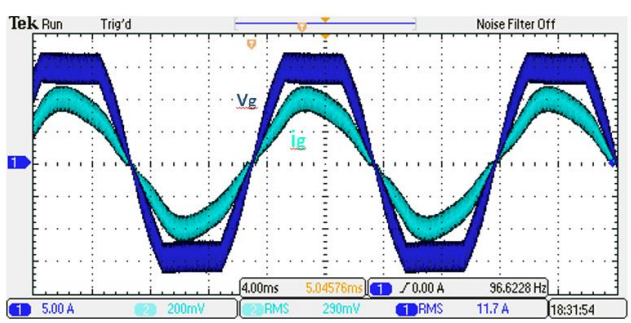

(b)

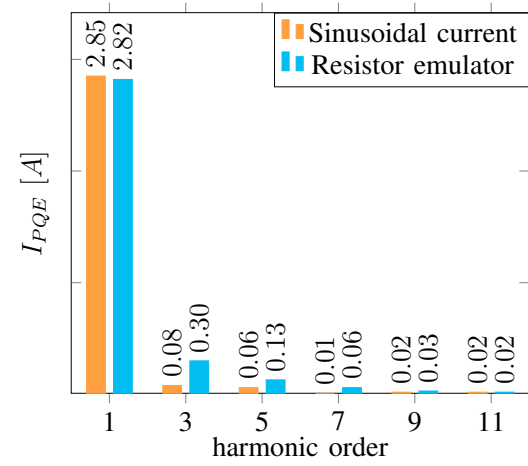

(c)

Fig. 9. Experimental results of PQE PFC at $60 \mathrm{~Hz}$. Voltage and current waveforms in a) resistor emulator mode $(k=0)$, b) sinusoidal current mode $(k=1)$ and $c)$ measured spectra in both operation modes.

depending on the application, either resistor emulator or low $T H D_{I}$.

To experimentally validate this proposal, the Boost converter has been tested under two input voltages (120 $V_{r m s}$ and $\left.230 V_{r m s}\right)$ and three input frequencies $(50 \mathrm{~Hz}, 60 \mathrm{~Hz}$ and $400 \mathrm{~Hz}$ ), with $12 \%$ harmonic distortion, for two different power levels (around $330 \mathrm{~W}$ and $800 \mathrm{~W}$ ), and $96 \mathrm{kHz}$ switching frequency. These situations have been tested with the $\mathrm{PQE}$ controller in both pure sinusoidal and resistor emulator behavior modes, and the results are summarized in Table I. A Pacific 345-AMX AC power source is used to supply the front-end stage with a distorted voltage. Different templates of distorted voltages are predefined. The $T H D_{I}$ results, which include all the harmonics required by the standards, are also provided by the AC power source. Comparing the results presented in Table I, it can be observed that the highest power factor values are obtained, as expected, with the resistor emulator behavior, with a $T H D_{I}$ similar to the $T H D_{V}$ of the input voltage; obtaining a power factor similar to the obtained with pure sinusoidal grid voltage. On the other hand, with the new proposal, the current harmonics are lower (above all $3^{\text {rd }}$ 
TABLE I

EXPERIMENTAL RESULTS UNDER DISTORTED LINE VoltAGE

\begin{tabular}{|c|c|c|c|c|c|c|}
\hline & \multirow{2}{*}{$\begin{array}{c}V_{P C C} \\
{[\mathrm{~V}]}\end{array}$} & \multirow{2}{*}{$\begin{array}{c}I_{P Q E} \\
{[A]} \\
\end{array}$} & \multirow{2}{*}{$\begin{array}{c}P_{P Q E}^{i n} \\
{[W]}\end{array}$} & \multirow{2}{*}{$\begin{array}{c}f \\
{[\mathrm{~Hz}]}\end{array}$} & \multicolumn{2}{|c|}{$T H D$} \\
\hline & & & & & $V_{P C C}[\%]$ & $I_{P Q E}[\%]$ \\
\hline \multicolumn{7}{|c|}{ Resistance behavior (traditional PFC controller approach) } \\
\hline Fig. 8.a & 226.2 & 3.64 & 820 & 50 & 12 & 11.5 \\
\hline Fig. 9.a & 117.3 & 2.85 & 329 & 60 & 12 & 10.8 \\
\hline Fig. 10.a & 225.5 & 3.6 & 800.9 & 400 & 12 & 11.33 \\
\hline \multicolumn{7}{|c|}{ Sinusoidal input current } \\
\hline Fig. 8.b & 226.1 & 3.7 & 823 & 50 & 12 & 4.2 \\
\hline Fig. 9.b & 117.3 & 2.88 & 329 & 60 & 12 & 3.4 \\
\hline Fig. 10.b & 225.5 & 3.6 & 800 & 400 & 12 & 2.93 \\
\hline
\end{tabular}

and $5^{\text {th }}$ harmonics) than the voltage ones and therefore the $T H D_{I}$ is also lower than the $T H D_{V}$.

Fig. 8.a and 8.b show the voltage and current waveforms of the PQE PFC in resistor emulator and sinusoidal current modes respectively at $50 \mathrm{~Hz}$. In resistor emulator mode the current waveform is proportional to the voltage one and, hence, current harmonics (the blue bars in Fig. 8.c) will generate voltage harmonics at the PCC due to $Z_{g}$ in Fig. 1 . By changing the operation mode to sinusoidal current one, the $T H D_{I}$ reduces from $11.5 \%$ to $4.2 \%$ and the current waveform in Fig. 8.b is almost sinusoidal but the zero crossing. Since the EPQ PFC active power is almost constant $(\approx 820 \mathrm{~W})$ in both operation modes, the fundamental input current must increase to compensate for the active power transferred by the current harmonics in the resistor emulator mode.

The proposed PQE PFC performance has also been evaluated in $60 \mathrm{~Hz}$ EPS, as it is shown in Fig. 9.a and 9.b. The results are similar to the $50 \mathrm{~Hz}$ case. Input current ripple is higher because the DC output voltage is intentionally lower in these tests to verify that the PQE controller performance does not depend on the output voltage level. As it is shown in Fig. 9.c, the input current spectra in both operation modes follow the behavior observed in the $50 \mathrm{~Hz}$ case.

Finally, in order to show the applicability of this approach to airplane EPS, the PQE PFC has been connected to a $400 \mathrm{~Hz}$ grid voltage and the obtained results are shown in Fig. 10. Again, the performance of the PQE PFC is consistent with the previous cases (Fig. 10.c). The results of all the cases are summarized in Table I.

The lower distortion observed as the line frequency increases is a consequence of the applied technique without current sensor [46]. This technique compensates for the current estimation errors acquired around the zero line crossing and therefore the accumulated error during half the line period becomes lower as the line frequency increases.

\section{CONCLUSION}

The consequence on the electrical power quality of connecting household appliances to the grid through PFC stages has been assessed considering different $T H D_{V}$ scenarios. As has been shown in (17) and (23), there are conditions under which sinusoidal current consumption results in better PF at the PCC than with resistor emulator behavior, commonly assumed to be ideal for PFC stages. A modification of the carrier signal of NLC controllers applied to PFC stages is designed to impress sinusoidal input current despite the input voltage distortion.

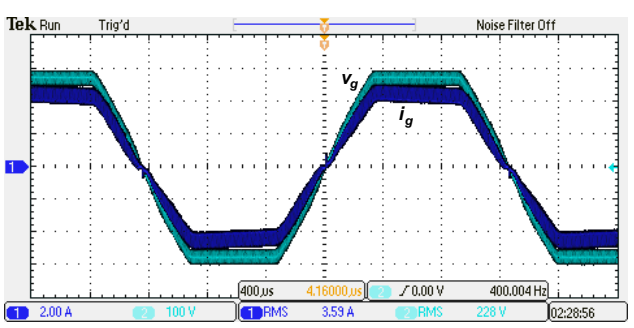

(a)

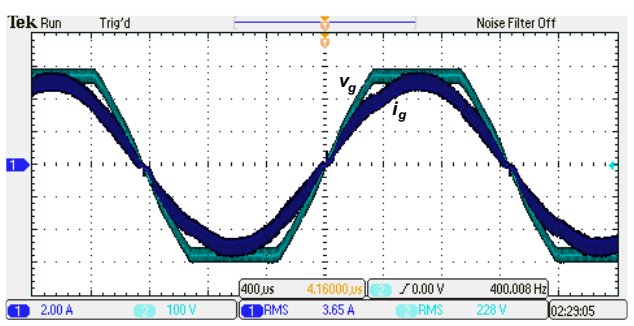

(b)

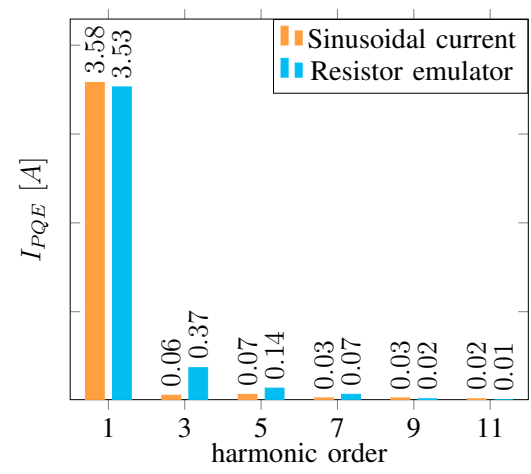

(c)

Fig. 10. Experimental results of PQE PFC at $400 \mathrm{~Hz}$. Voltage and current waveforms in a) resistor emulator mode $(k=0)$, b) sinusoidal current mode $(k=1)$ and $c)$ measured spectra in both operation modes.

The line current estimation with no interaction with the power stage implements the NLC with high noise immunity. The digital implementation of the non-linear controller is appropriate to define the carrier and to include additional reduction of the current distortion depending on the application. The PQE controller can be applied to mitigate the effect of nonlinear loads within household appliances on residential electrical grids. The operation mode of the digital controller can be autonomously adjusted through the locally measured $T H D_{V}$, without extra circuitry. The user or a $T H D_{V}$ threshold detection selects the convenient behavior (either resistor emulator or pure sinusoidal current). Experimental results obtained with high $T H D_{V}$ (above $5 \%$ ) confirm the feasibility of the PQE controller in both sinusoidal current and resistive emulator modes.

\section{REFERENCES}

[1] IEEE Std. 519-2014 (Revision of IEEE Std. 519-1992), IEEE Recommended Practice and Requirements for Harmonic Control in Electric Power Systems, DOI 10.1109/IEEESTD.2014.6826459, pp. 1-29, Jun. 2014. 
[2] Y. J. Wang, R. M. O'Connell, and G. Brownfield, "Modeling and prediction of distribution system voltage distortion caused by nonlinear residential loads," IEEE Trans. Power Del., vol. 16, DOI 10.1109/61.956765, no. 4, pp. 744-751, Oct. 2001.

[3] H. Oraee, "A quantitative approach to estimate the life expectancy of motor insulation systems," IEEE Trans. Dielectr. Electr. Insul., vol. 7, DOI 10.1109/94.891990, no. 6, pp. 790-796, Dec. 2000.

[4] D. Fabiani and G. C. Montanari, "The effect of voltage distortion on ageing acceleration of insulation systems under partial discharge activity," IEEE Electr. Insul. Mag., vol. 17, DOI 10.1109/57.925300, no. 3, pp. 24-33, May. 2001.

[5] T. J. Dionise and V. Lorch, "Harmonic filter analysis and redesign for a modern steel facility with two melt furnaces using dedicated capacitor banks," in IEEE IAS Annual Meeting, vol. 1, DOI 10.1109/IAS.2006.256496, pp. 137-143, Oct. 2006.

[6] D. Ramirez-Castro, E. O'Neill-Carrillo, and J. Santiago-Perez, "Assessment of harmonics at a medical facility," in IEEE International Conference on Harmonics and Quality of Power, vol. 2, DOI 10.1109/ICHQP.2000.897750, pp. 619-624, 2000.

[7] U. Rao, S. N. Singh, and C. K. Thakur, "Power quality issues with medical electronics equipment in hospitals," in IEEE International Conference on Industrial Electronics, Control and Robotics, DOI 10.1109/IECR.2010.5720150, pp. 34-38, Dec. 2010.

[8] K. D. McBee and M. G. Simões, "General smart meter guidelines to accurately assess the aging of distribution transformers," IEEE Trans. Smart Grid, vol. 5, DOI 10.1109/TSG.2014.2320285, no. 6, pp. 2967 2979, Nov. 2014.

[9] H. E. Mazin, E. E. Nino, W. Xu, and J. Yong, "A study on the harmonic contributions of residential loads," IEEE Trans. Power Del., vol. 26, DOI 10.1109/TPWRD.2010.2096236, no. 3, pp. 1592-1599, Jul. 2011.

[10] S. Munir and Y. W. Li, "Residential distribution system harmonic compensation using PV interfacing inverter," IEEE Trans. Smart Grid, vol. 4, DOI 10.1109/TSG.2013.2238262, no. 2, pp. 816-827, Jun. 2013.

[11] M. S. Munir, Y. W. Li, and H. Tian, "Improved residential distribution system harmonic compensation scheme using power electronics interfaced DGs," IEEE Trans. Smart Grid, vol. 7, DOI 10.1109/TSG.2016.2535213, no. 3, pp. 1191-1203, May. 2016.

[12] N. Saxena, I. Hussain, B. Singh, and A. L. Vyas, "Implementation of grid integrated PV-battery system for residential and electrical vehicle applications," IEEE Trans. Ind. Electron., vol. PP, DOI 10.1109/TIE.2017.2739712, no. 99, p. 1, 2017

[13] T. L. Lee and P. T. Cheng, "Design of a new cooperative harmonic filtering strategy for distributed generation interface converters in an islanding network," IEEE Trans. Power Electron., vol. 22, DOI 10.1109/TPEL.2007.904200, no. 5, pp. 1919-1927, Sep. 2007.

[14] A. Micallef, M. Apap, C. Spiteri-Staines, J. M. Guerrero, and J. C. Vasquez, "Reactive power sharing and voltage harmonic distortion compensation of droop controlled single phase islanded microgrids," IEEE Trans. Smart Grid, vol. 5, DOI 10.1109/TSG.2013.2291912, no. 3, pp. 1149-1158, May. 2014.

[15] A. Micallef, M. Apap, C. Spiteri-Staines, and J. M. Guerrero, "Mitigation of harmonics in grid-connected and islanded microgrids via virtual admittances and impedances," IEEE Trans. Smart Grid, vol. 8, DOI 10.1109/TSG.2015.2497409, no. 2, pp. 651-661, Mar. 2017.

[16] J. He, Y. W. Li, F. Blaabjerg, and X. Wang, "Active harmonic filtering using current-controlled, grid-connected DG units with closedloop power control," IEEE Trans. Power Electron., vol. 29, DOI 10.1109/TPEL.2013.2255895, no. 2, pp. 642-653, Feb. 2014

[17] A. Javadi, A. Hamadi, L. Woodward, and K. Al-Haddad, "Experimental investigation on a hybrid series active power compensator to improve power quality of typical households," IEEE Trans. Ind. Electron., vol. 63, DOI 10.1109/TIE.2016.2546848, no. 8, pp. 4849-4859, Aug. 2016.

[18] A. Javadi, A. Hamadi, A. Ndtoungou, and K. Al-Haddad, "Power quality enhancement of smart households using a multilevel-THSeAF with a PR controller," IEEE Trans. Smart Grid, vol. 8, DOI 10.1109/TSG.2016.2608352, no. 1, pp. 465-474, Jan. 2017.

[19] A. Javadi, L. Woodward, and K. Al-Haddad, "Real-time implementation of a three-phase THSeAF based on VSC and P+R controller to improve power quality of weak distribution systems," IEEE Trans. Power Electron., vol. PP, DOI 10.1109/TPEL.2017.2697821, no. 99, p. 1, 2017.

[20] Y. Tang, P. C. Loh, P. Wang, F. H. Choo, F. Gao, and F. Blaabjerg, "Generalized design of high performance shunt active power filter with output LCL filter," IEEE Trans. Ind. Electron., vol. 59, DOI 10.1109/TIE.2011.2167117, no. 3, pp. 1443-1452, Mar. 2012.

[21] A. Anurag, Y. Yang, and F. Blaabjerg, "Thermal performance and reliability analysis of single-phase PV inverters with reactive power injection outside feed-in operating hours," IEEE J. Emerg. Sel. Top.
Power Electron., vol. 3, DOI 10.1109/JESTPE.2015.2428432, no. 4, pp. 870-880, Dec. 2015.

[22] D. He, L. Du, Y. Yang, R. Harley, and T. Habetler, "Front-end electronic circuit topology analysis for model-driven classification and monitoring of appliance loads in smart buildings," IEEE Trans. Smart Grid, vol. 3, DOI 10.1109/TSG.2012.2219327, no. 4, pp. 2286-2293, Dec. 2012.

[23] K. D. Gusseme, W. R. Ryckaert, D. M. V. de Sype, J. A. Ghijselen, J. A. Melkebeek, and L. Vandevelde, "A boost PFC converter with programmable harmonic resistance," IEEE Trans. Ind. Appl., vol. 43, DOI 10.1109/TIA.2007.895765, no. 3, pp. 742-750, May. 2007.

[24] W. Zhang, G. Feng, Y.-F. Liu, and B. Wu, "A digital power factor correction (PFC) control strategy optimized for DSP," IEEE Trans. Power Electron., vol. 19, DOI 10.1109/TPEL.2004.836675, no. 6, pp. 1474-1485, Nov. 2004.

[25] A. Karaarslan and I. Iskender, "Average sliding control method applied on power factor correction converter for decreasing input current total harmonic distortion using digital signal processor," IET Power Electron., vol. 5, DOI 10.1049/iet-pel.2011.0348, no. 5, pp. 617-626, May. 2012.

[26] M. Rajesh and B. Singh, "Analysis, design and control of single-phase three-level power factor correction rectifier fed switched reluctance motor drive," IET Power Electron., vol. 7, DOI 10.1049/iet-pel.2013.0621, no. 6, pp. 1499-1508, Jun. 2014.

[27] W. Zhang, Y. f. Liu, and B. Wu, "A new duty cycle control strategy for power factor correction and FPGA implementation," IEEE Trans. Power Electron., vol. 21, DOI 10.1109/TPEL.2006.882922, no. 6, pp. 1745-1753, Nov. 2006.

[28] N. R. Zargari and G. Joos, "Performance investigation of a currentcontrolled voltage-regulated PWM rectifier in rotating and stationary frames," IEEE Trans. Ind. Electron., vol. 42, DOI 10.1109/41.402479, no. 4, pp. 396-401, Aug. 1995.

[29] D. J. Tooth, S. J. Finney, and B. W. Williams, "Effects of using DC-side average current-mode control on a three-phase converter with an input filter and distorted supply," IEE Proc.-Electr. Power Appl., vol. 147, DOI 10.1049/ip-epa:20000625, no. 6, pp. 459-467, Nov. 2000.

[30] D. Mukherjee and D. Kastha, "Voltage sensorless control of the threelevel three-switch Vienna rectifier with programmable input power factor," IET Power Electron., vol. 8, DOI 10.1049/iet-pel.2014.0365, no. 8, pp. 1349-1357, 2015.

[31] H. C. Chen, C. C. Lin, and J. Y. Liao, "Modified single-loop current sensorless control for single-phase boost-type SMR with distorted input voltage," IEEE Trans. Power Electron., vol. 26, DOI 10.1109/TPEL.2010.2070079, no. 5, pp. 1322-1328, May. 2011.

[32] A. Sanchez, A. de Castro, V. M. López, F. J. Azcondo, and J. Garrido, "Single ADC digital PFC controller using precalculated duty cycles,' IEEE Trans. Power Electron., vol. 29, DOI 10.1109/TPEL.2013.2256931, no. 2, pp. 996-1005, Feb. 2014.

[33] H. C. Chen, "Interleaved current sensorless control for multiphase boosttype switch-mode rectifier with phase-shedding operation," IEEE Trans. Ind. Electron., vol. 61, DOI 10.1109/TIE.2013.2257137, no. 2, pp. 766775, Feb. 2014.

[34] H. C. Chen and J. Y. Liao, "Multiloop interleaved control for threelevel switch-mode rectifier in AC/DC applications," IEEE Trans. Ind. Electron., vol. 61, DOI 10.1109/TIE.2013.2278961, no. 7, pp. 32103219, Jul. 2014.

[35] N. U. Hassan, Y. I. Khalid, C. Yuen, and W. Tushar, "Customer engagement plans for peak load reduction in residential smart grids," IEEE Trans. Smart Grid, vol. 6, DOI 10.1109/TSG.2015.2404433, no. 6, pp. 3029-3041, Nov. 2015.

[36] Y. Guo, M. Pan, Y. Fang, and P. P. Khargonekar, "Decentralized coordination of energy utilization for residential households in the smart grid," IEEE Trans. Smart Grid, vol. 4, DOI 10.1109/TSG.2013.2268581, no. 3, pp. 1341-1350, Sep. 2013.

[37] V. M. López and F. J. Azcondo, "Low $T H D_{I}$ front-end stage under non-sinusoidal voltage," in IEEE Workshop on Control and Modeling for Power Electronics, DOI 10.1109/COMPEL.2013.6626439, pp. 1-7, Jun. 2013.

[38] D. Salles, C. Jiang, W. Xu, W. Freitas, and H. E. Mazin, "Assessing the collective harmonic impact of modern residential loads -Part I: Methodology," IEEE Trans. Power Del., vol. 27, DOI 10.1109/TPWRD.2012.2207132, no. 4, pp. 1937-1946, Oct. 2012.

[39] IEEE Std 1459-2010 (Revision of IEEE Std 1459-2000), IEEE Standard Definitions for the Measurement of Electric Power Quantities Under Sinusoidal, Nonsinusoidal, Balanced, or Unbalanced Conditions, DOI 10.1109/IEEESTD.2010.5439063, no. 1459-2010, pp. 1-50, Mar. 2010.

[40] Y. J. Wang, R. M. O'Connell, and G. Brownfield, "Modeling and prediction of distribution system voltage distortion caused by non- 
linear residential loads," IEEE Power Eng. Rev., vol. 21, DOI 10.1109/MPER.2001.4311492, no. 7, p. 71, Jul. 2001.

[41] A. B. Nassif, J. Yong, and W. Xu, "Measurement-based approach for constructing harmonic models of electronic home appliances," IET Gener. Transm. Distrib., vol. 4, DOI 10.1049/iet-gtd.2009.0240, no. 3, pp. 363-375, Mar. 2010.

[42] J. He and Y. W. Li, "Analysis, design, and implementation of virtual impedance for power electronics interfaced distributed generation," IEEE Trans. Ind. Appl., vol. 47, DOI 10.1109/TIA.2011.2168592, no. 6, pp. 2525-2538, Nov. 2011.

[43] D. Maksimovic, Y. Jang, and R. W. Erickson, "Nonlinear-carrier control for high-power-factor boost rectifiers," IEEE Trans. Power Electron., vol. 11, DOI 10.1109/63.506123, no. 4, pp. 578-584, Jul. 1996.

[44] R. Zane and D. Maksimovic, "Nonlinear-carrier control for high-powerfactor rectifiers based on up-down switching converters," IEEE Trans. Power Electron., vol. 13, DOI 10.1109/63.662824, no. 2, pp. 213-221, Mar. 1998

[45] B. A. Mather and D. Maksimović, "A simple digital power-factor correction rectifier controller," IEEE Trans. Power Electron., vol. 26, DOI 10.1109/TPEL.2010.2051458, no. 1, pp. 9-19, Jan. 2011.

[46] V. M. Lopez, F. J. Azcondo, A. de Castro, and R. Zane, "Universal digital controller for boost CCM power factor correction stages based on current rebuilding concept," IEEE Trans. Power Electron., vol. 29, DOI 10.1109/TPEL.2013.2280077, no. 7, pp. 3818-3829, Jul. 2014.

[47] V. M. López Martín, "Digital power factor correction based on linecurrent estimation: CCM boost converter application," phdthesis, University of Cantabria, Nov. 2013.

[48] J. Sun, "Analysis and design of single-phase PFC converters for airborne systems," in IEEE Industrial Electronics Conference, vol. 2, DOI 10.1109/IECON.2003.1280199, pp. 1101-1109, Nov. 2003.

[49] J. Sun, M. Chen, and K. J. Karimi, "Aircraft power system harmonics involving single-phase PFC converters," IEEE Trans. Aerosp. Electron. Syst., vol. 44, DOI 10.1109/TAES.2008.4517000, no. 1, pp. 217-226, Jan. 2008.

[50] J. Sebastian, D. G. Lamar, M. A. P. de Azpeitia, M. Rodriguez, and A. Fernandez, "The voltage-controlled compensation ramp: A waveshaping technique for power factor correctors," IEEE Trans. Ind. Appl., vol. 45, DOI 10.1109/TIA.2009.2018935, no. 3, pp. 1016-1027, May. 2009.

[51] F. J. Azcondo, A. de Castro, V. M. Lopez, and O. Garcia, "Power factor correction without current sensor based on digital current rebuilding," IEEE Trans. Power Electron., vol. 25, DOI 10.1109/TPEL.2009.2039231, no. 6, pp. 1527-1536, Jun. 2010.

[52] J. P. Gegner and C. Q. Lee, "Linear peak current mode control: a simple active power factor correction control technique for continuous conduction mode," in IEEE Power Electronics Specialists Conference, vol. 1, DOI 10.1109/PESC.1996.548581, pp. 196-202, Jun. 1996.

[53] A. Sanchez, A. de Castro, F. López-Colino, and J. Garrido, "Comparison of AC mains synchronization methods when using precalculated duty cycles in power factor correction," in IEEE Workshop on Control and Modeling for Power Electronics, DOI 10.1109/COMPEL.2014.6877203, pp. 1-4, Jun. 2014.

[54] D. Hogan, F. Gonzalez-Espin, J. Hayes, G. Lightbody, and R. Foley, "An adaptive digital control scheme for improved active power filtering under distorted grid conditions," IEEE Trans. Ind. Electron., vol. PP, DOI 10.1109/TIE.2017.2726992, no. 99, p. 1, 2017.

[55] S. Golestan, J. M. Guerrero, and J. C. Vasquez, "A robust and fast synchronization technique for adverse grid conditions," IEEE Trans. Ind. Electron., vol. 64, DOI 10.1109/TIE.2016.2636206, no. 4, pp. 3188 3194, Apr. 2017.

[56] F. Lopez, P. Lamo, F. Azcondo, and A. Pigazo, "Sensorless control of a bridgeless PFC using a low pass filter model and a linear PR controller," in PCIM Europe, pp. 1-6, May. 2017.

[57] P. Lamo, F. López, A. Pigazo, and F. J. Azcondo, “An efficient FPGA implementation of a quadrature signal-generation subsystem in SRF PLLs in single-phase PFCs," IEEE Trans. Power Electron., vol. 32, DOI 10.1109/TPEL.2016.2582534, no. 5, pp. 3959-3969, May. 2017.

[58] Y. Wang, J. Yong, Y. Sun, W. Xu, and D. Wong, "Characteristics of harmonic distortions in residential distribution systems," IEEE Trans. Power Del., vol. 32, DOI 10.1109/TPWRD.2016.2606431, no. 3, pp. 1495-1504, Jun. 2017.

[59] R. Matusiak, "Implementing Fast Fourier Transform algorithms of realvalued sequences with the TMS320 DSP platform," Texas Instruments, techreport SPRA291, Aug. 2001.

[60] "LogiCORE IP Fast Fourier Transform v7.1," Mar. 2011, product specification DS260.

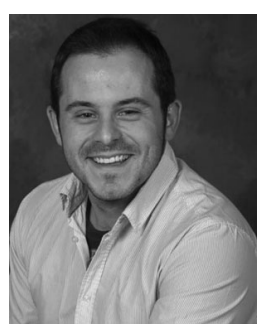

Víctor M. López-Martín (S'10) was born in Torrelavega, Cantabria, Spain, in 1985. He received the Electronics and Control Engineering degree from the University of Cantabria, Santander, Spain, in 2009, and the Power Electronics $\mathrm{PhD}$ degree from University of Cantabria in 2013.

From June to September 2012, he was a Visiting Scholar in the Colorado Power Electronics Center (CoPEC), University of Colorado at Boulder, and from September to December 2012 at the Utah State University Power Laboratory, Logan, USA. Both periods with the Professor R. Zane as an Advisor. Since 2015 he is working as Power Electronics designer in IK4-Ikerlan, in the Power Electronics area. $\mathrm{His}$ research interests include $\mathrm{SiC}$ power modules, power converters for traction and renewable energy applications, and resonant converters.

Dr. López received the IEEE/IEL Electronic Library Award in 2009.

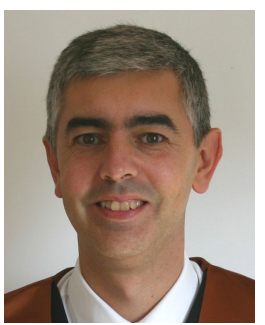

Francisco J. Azcondo (S'90-M'92-SM'00) received the Electrical Engineering degree from the Universidad Politécnica de Madrid, Madrid, Spain, in 1989, and the Ph.D. degree from the University of Cantabria, Santander, Spain, in 1993. He was a Visiting Researcher with the Department of Electrical, Computer, and Energy Engineering, University of Colorado, Boulder CO, USA, from 2004 to 2010, the Department of Electronics and Communication Engineering, University of Toronto, Toronto, ON, Canada, in 2006, and the Utah State University Power Electronics Laboratory, Department of Electronics and Communication Engineering, Utah State University, Logan, UT, USA, in 2013. Since 2004, he has been a Special Member (appointed as a Graduate Faculty) with the Department of Electrical, Computer, and Energy Engineering, University of Colorado, renovated until 2017.

$\mathrm{He}$ is currently a Professor with the Department of Electronics Technology, Systems and Automation Engineering, and Dean of the School of Industrial and Telecommunications Engineering, University of Cantabria. His current research interests include modeling and control of switch-mode power converters and resonant converters, digital control capabilities for switched-mode power supplies, and current sensorless control for grid connected converters and applications, such as outdoor lighting, electrical discharge machining, and arc welding.

Dr. Azcondo has been the Chair of the IEEE Industrial Electronics Society - Power Electronics Society Spanish Joint Chapter from 2008 to 2011. He is an Associate Editor of the IEEE Transaction on Power Electronics, the IEEE Journal of Emerging and Selected Topics in Power Electronics, and the IEEE Transaction on Industrial Electronics.

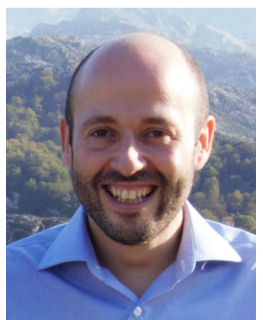

Alberto Pigazo (M'05-SM'14) was born in Santander, Spain. He received the M.Sc. and Ph.D. degrees in physics (electronics) from the University of Cantabria, Santander, Spain, in 1997 and 2004 respectively.

Since 2012 he has been an Associate Professor with the Dept. of Computer Science and Electronics, University of Cantabria. He was a guest researcher at the Power Electronics Laboratory, Polytechnic of Bari, Italy, in 2007, and a visiting professor at the Center of Reliable Power Electronics, Dept. of Energy Technology, Aalborg University, Denmark, in 2013, and the Chair of Power Electronics, Christian-Albrecht University of Kiel, Germany, in 2013. His research interests include active power filtering, power converters for grid integration of renewable energy sources and power electronics for ships. 